\title{
Exploring Second Language Vocabulary Learning in ESL Classes
}

\author{
Haifa H. Alghamdi ${ }^{1}$ \\ ${ }^{1}$ College of Education,-TESOL, Seattle University, Seattle, WA, United States \\ Correspondence: Haifa H. Alghamdi, College of Education,-TESOL, Seattle University, Seattle, WA, United \\ States.
}

Received: November 6, 2018 Accepted: December 8, 2018 Online Published: December 11, 2018

doi: 10.5539/elt.v12n1p78

URL: https://doi.org/10.5539/elt.v12n1p78

\begin{abstract}
This research investigates how foreign language learners learn vocabulary in an English as a Second Language (ESL) classroom. The participants are eleven foreign students from an advanced ESL Reading class in Edmonds Community College in Lynnwood, WA. A questionnaire was used as an instrument to inquire about the students' vocabulary learning methods. The results of the study proved that students are more engaged and motivated during group work activities and they learn more vocabulary from reading classes. The study concludes with pedagogical implications that ESL teachers might consider when teaching vocabulary in their ESL classrooms.
\end{abstract}

Keywords: vocabulary teaching, vocabulary learning, vocabulary acquisition, ESL learning, group work, foreign language learners

\section{Introduction}

Vocabulary teaching and learning was given a second or even little priority in English as a second language classes and English as a foreign language classes (ESL/EFL). Recently, however, there has been a renewed interest in the nature of vocabulary and its role in learning the target language (Maftoon, Hamidi, \& Sarem, 2012). Acquiring vocabulary is essential for communicative competence and one of the central tasks for second language learners. Therefore, the process of learning the words remains the first step in acquiring any language. Vocabulary acquisition and its most effective means, have been the focus of investigations in the field of Second Language Acquisition (SLA) (Xu, 2010).

\subsection{Statement of the Problem}

Vocabulary learning can be difficult for English language students. English language learners tend to learn their vocabulary from the ESL classroom or incidentally by pick it up outside of the classroom. Hence, this research paper aims to investigate how second language learners tend to learn and acquire their English vocabulary.

\subsection{Purpose of the Study}

This study reports unexpectedly useful learning methods that some ESL students use in their attempt to learn English vocabulary. The objectives of this study are: (1) to determine how vocabulary is learned then acquired in ESL settings, and (2) to determine the favorite learning methods that ESL learners prefer in learning vocabulary.

\subsection{Definition of Terms}

English as a Second Language (ESL): Learned English language by non-native speakers in an English-speaking environment (Nordquist, 2018).

English as a Foreign Language (EFL): Learned English language while living in a community where the English is not spoken as a first language (Alsubaie \& Ashuraidah, 2017).

Formative Assessment: An instrument or a tool used in evaluations of student comprehension, learning needs, and academic progress during a lesson, unit, or course (Bennett, 2011).

Second Language Acquisition (SLA): Refers to the study of how students learn a second language (L2)

In addition to their first language (L1) (Stefansson, 2013).

\section{Review of Literature}

Acquiring and mastering new vocabulary can be very difficult for ESL and EFL learners. Great attention was paid to the most effective learning strategies especially in the research of second language and foreign language 
classes. Newton (2013) and Xu (2010) have discussed the incidental vocabulary acquisition from two different perspectives. In Newton's study, the participants enrolled in a 12-week, pre-entry, intensive academic English language program at a university in New Zealand. The study investigated the ways in which two groups of four adult learners of English as a second language (ESL) responded to unfamiliar words they encountered in four communication tasks. It also examined the effect that different levels of engagement with these words (including negotiation of form and meaning) had on subsequent recall of word meaning. Of the four tasks, two were information gap tasks and two were opinion gap tasks. The results showed a strong task type effect on both the amount and type of negotiation, with more negotiation of the form of words (including spelling and pronunciation) in the information gap tasks and, conversely, more negotiation of meaning in the opinion gap tasks. Through the negotiation process, the learners in the study provided accurate information to each other on word meaning. However, only a small proportion of the total number of unfamiliar words in the tasks were actually negotiated for meaning. The prediction that negotiated words would be more likely to be learnt was confirmed, although the learners also showed an improved recall of many words that had not been negotiated. In addition, $59 \%$ of the students demonstrated a good quality of responses to requests for clarification of unfamiliar words. Ultimately, two important findings from the study are worth highlighting. First, the type of the task affected the kind of attention paid to unfamiliar vocabulary. The processes required by the different task types in the study, influenced the degree to which the learners focused their negotiation on the meaning or the form of the vocabulary task. Second, negotiation did not account for most learning. The learning of unfamiliar words occurred in three ways in the study, all of them were of significance in communication tasks: learning through meeting unfamiliar words in context, learning through negotiation, and learning through observing negotiation.

$\mathrm{Xu}$ (2010), however, has discussed the incidental learning from a different approach, which was through investigating the effect of dictionary on the incidental vocabulary acquisition (IVA). Xu (2010) aimed to answer the following questions in his research: 1) Does the use of dictionary have a positive effect on the IVA in reading the material without glosses? 2) Do the paper dictionary and the electronic dictionary have similar impact on the immediate word gains and retention of learners? The subjects were 60 freshmen who were learning English as a second language in Qingdao University of Science and Technology. Students were divided into two groups according to their score of English in college entrance examination. Students in the first group used paper dictionaries and students in the second group used electronic dictionaries, to see which kind of dictionaries contribute more to the incidental learning of vocabulary. The material selected was a reading material with ten unfamiliar words. The results of this study showed that the consultation of dictionary had a positive impact on vocabulary learning and reading development, and therefore, the researcher encouraged the use of dictionaries in a consistent and appropriate manner. Finally, the researcher stated that the paper dictionary was better than the electronic dictionary in incidental vocabulary acquisition, because word meanings can be elaborated deeply and were easier to be remembered.

In addition, many studies have discussed the role of extensive reading in enhancing vocabulary. The benefits of extensive reading (ER) have been widely documented in studies that ranged from large-scale implementations across whole school districts (e.g., Elley, 1991; Lightbown, 1992) to case studies of single readers (e.g., Cho \& Krashen, 1994; Parry, 1991). A perfect example is the study conducted by Horst (2005), in which he examined the effect of ER programs on vocabulary growth. His article described a way of tackling a measurement challenge using electronic scanning, lexical frequency profiling, and individualized checklist testing. Twenty-one ESL learners freely chose books that interested them. In his article, however, Horst demonstrated the limitations that incidental acquisition of new vocabulary through reading had. He stated that participants were typically asked to read a text, usually with the expectation that some sort of evaluation task will follow, but they did not realize that this will be a test of words that occurred in the passage. These read-and-test studies clearly documented learners' knowledge of specific words that learners have encountered in reading a text (rather than the more general language gains documented in most ER studies). The results of this study showed that there was an indication of new full or partial knowledge in 18 instances. Responses such as 'one kind of drink' for rum or 'way' for lane were considered evidence of partial knowledge. However, ER research reported relatively little information about the vocabulary-expanding effects of reading extensively in a second language, simply because it tends to focus on other, more general aspects of language development (Horst, 2005).

Most vocabulary teaching literature advises learners to keep vocabulary notebooks to help promote vocabulary acquisition as well as learner autonomy. Yet, there have been few studies of the vocabulary notebooks kept by students studying English as a foreign language. McCrostie (2007), for example, conducted a study where he examined vocabulary notebooks kept by 124 first year students majoring in English at a Japanese university. The study aimed to determine: (1) the sources from which students choose words, (2) the types and frequency of 
words selected, and (3) the reasoning behind word selection. The findings of this study classified the sources that students drew their vocabulary items from, into five broad categories: (1) textbooks and class handouts, (2) other written sources (books, newspapers, magazines), (3) electronic media (music, TV, movies), (4) conversations, and (5) other (including signs, Internet, computer games, dictionaries). The majority of words ( $82 \%$ ) came from textbooks and class handouts, since these books were their first resources of learning the language. Students also chose some words from other written sources (6.5\%) and (5\%) form the electronic media (mainly music CDs). Only $2 \%$ of the words came from listening or engaging in conversation. Finally, $4.5 \%$ of the words came from other sources. On the other hand, the examination of the notebooks revealed how many words from each part of speech students preferred. Nouns proved to be the most popular word class. Out of 17,483 words, about $43 \%$ were nouns. The highest percentage of nouns recorded by an individual student was $54 \%$ and the lowest was $30 \%$. Results indicate that students tend to record Nouns more than any other part of speech, and this study showed that teachers should spend more time guiding their students to the proper use of vocabulary notebooks.

\section{Method}

\subsection{Participants}

The participants in this study were eleven international students. Two students from Saudi Arabia, two from Korea, Three from China, one student from Vietnam, one from Japan, one from Turkey, and one student from France. Their level was an upper-intermediate level, and they have been studying in the ESL program for one year. Prior to that, students were not acquainted with academic English. The study was conducted in an advanced ESL reading class in Edmonds Community College in Lynnwood, WA. The sampling techniques used in selecting the participants in the study were a mix of convenience and purposive sampling. Convenience sampling (also known as Haphazard Sampling or Accidental Sampling) is a type of nonprobability or nonrandom sampling where members of the target population that meet certain practical criteria, such as easy accessibility, geographical proximity, availability at a given time, or the willingness to participate are included for the purpose of the study (Etikan, Musa, \& Alkassim, 2015).

All of the students were at the same college, which made it a convenience sampling, and they were selected for a purpose. The purposive sampling technique (also called judgment sampling), on the other hand, it is the purposeful choice of a participant due to the qualities the participant possesses. It is a nonrandom technique that requires the researcher to decide what needs to be known and sets out to find people who can and are willing to provide the information by virtue of knowledge or experience (Etikan, Musa, \& Alkassim, 2015).The sampling could also be stratified random sampling because I considered having as much cultural backgrounds as possible. I was looking for culturally inclusive group of students so the results of this study can somehow be generalized to other ESL settings with similar learning environment.

\subsection{Instruments}

This research was conducted to examine how ESL students learn vocabulary. There were two instruments used to investigate the learning behavior, (1) a class observation and (2) a questionnaire that was distributed by the end of the observed class.

\subsection{Procedure}

\subsubsection{Class Observation}

During the observation, students were sitting in groups (on round tables), demonstrating a collaborative learning style. The class agenda had four important vocabulary introductions and exercises: (1) a vocabulary matching exercise, (2) a vocabulary in context exercise, (3) a photograph exercise, and (4) a paraphrasing exercise. In the matching exercise, students were given a worksheet with two columns. In column (A), 14 vocabulary words were given (students were unfamiliar with the given words), and in column (B), the possible synonyms or definitions that could match the 14 words in column (A) were presented. In this exercise, students were within groups but working individually. Afterwards, students were asked to work in pairs and help each other on completing the task, and the class teacher monitored their language behavior. Eventually, they shared their answers with the teacher and the rest of the class. During this task, the teacher was trying to provide students with techniques that would better help students' memory in mastering vocabulary, which is what He, H., and Deng (2015) recommended in their article on Mental Lexicon. For example, the teacher in the observed class taught his students that suffixes and roots could tell the possible meaning of the word even if they were not familiar with the word. For example, he introduced the prefix amb (e.g. ambiguous), as around, about or both.

In the vocabulary in context exercise, however, the teacher distributed a handout and asked the students to work with a partner (in pairs) to re-read an article, and answer the questions in a given handout to help them guess and 
understand the vocabulary words in context. The questions in the handout were linking vocabulary words to the part of speech like, what part of speech commonly ends with al? Additionally, the questions were directly linking vocabulary to context by asking students to read a line in the reading article and guess the meaning of the given word from the context. For instance, read line 21 and list all the titles one man can have? Further, the teacher tried to make sure that students understand him when he refered to the word context. He asked his students: when we as reading teachers ask you to guess from context, what do we mean?

Furthermore, students were given the remaining two exercises on vocabulary. First, a photograph exercise that the teacher presented. The pictures were related to a chapter in the book called who you are? In this activity, students were in groups and the teacher presented pictures of a doctor, a nurse, a band, and a pilot. Then he asked the students what do you see? What do you know about the people in the pictures? And how do you know? The teacher was trying to test the students' knowledge of titles and discuss variety of information related to the pictures, to enhance students' practice of vocabulary learning. Second, the teacher conducted a paraphrasing exercise, in which he asked the students to work individually and use their own words to refer or explain the same words written in the given work sheet. Students were encouraged to use their own words to give an idea of the article and summarize it. For instance, paraphrase the main idea and summarize the article. The teacher did not share the answers with the students; he administered the activity and guided few students through the questions

\subsubsection{Questionnaire}

How do you learn vocabulary? was the title of the questionnaire which was distributed to the students at the end of the class and consisted of five questions. The first four questions were multiple choice and the last question required a short answer (See Appendix).

\section{Results}

The results of this study was highly unpredictable. Students stated that they usually learn more vocabulary from outside the classroom than they learn from most of basic skills classes (e.g. listening speaking, and writing). In educational settings, on the other hand, students confirmed that they learn most of the vocabulary taught to them in Reading classes.

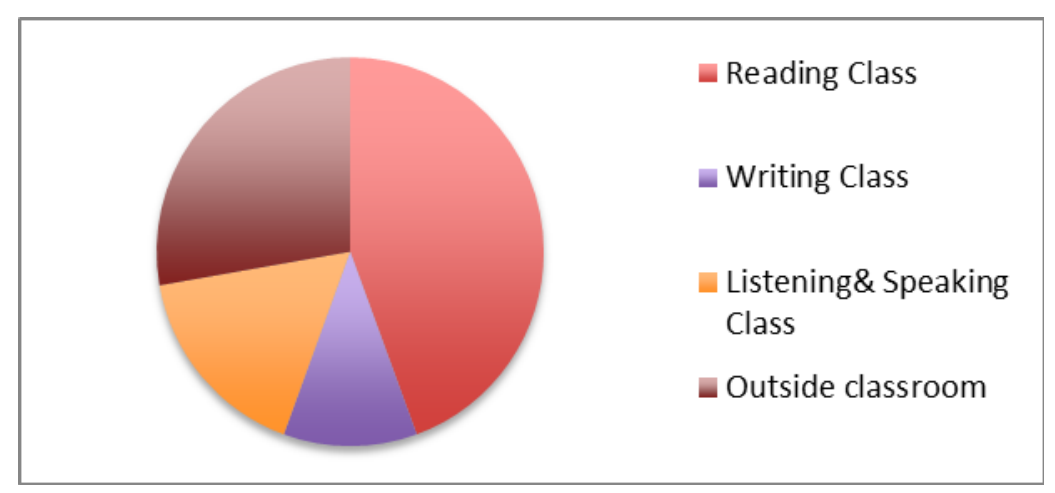

Figure 1. Disciplines that students learn their vocabulary from

Figure 1 shows that $44 \%$ of the students are learning most of their vocabulary from Reading classes. In addition, $28 \%$ of the students stated that they learn more vocabulary from outside the classroom, which is a large percentage compared to other disciplines. On the other hand, writing and listening \& speaking classes were the least domains students learn their vocabulary from, with $17 \%$ and $11 \%$ respectively. However, a threat to validity is anticipated in the results of this section of the questionnaire. Since the participants were in a reading class, students may have said they usually learn more vocabulary from Reading classes, just because they were in the reading class and they thought it's the correct answer. They may be figured that it is preferable to choose reading over any other discipline, and consequently; the results could be biased. Moreover, the sample size is not large enough to generalize this study. 


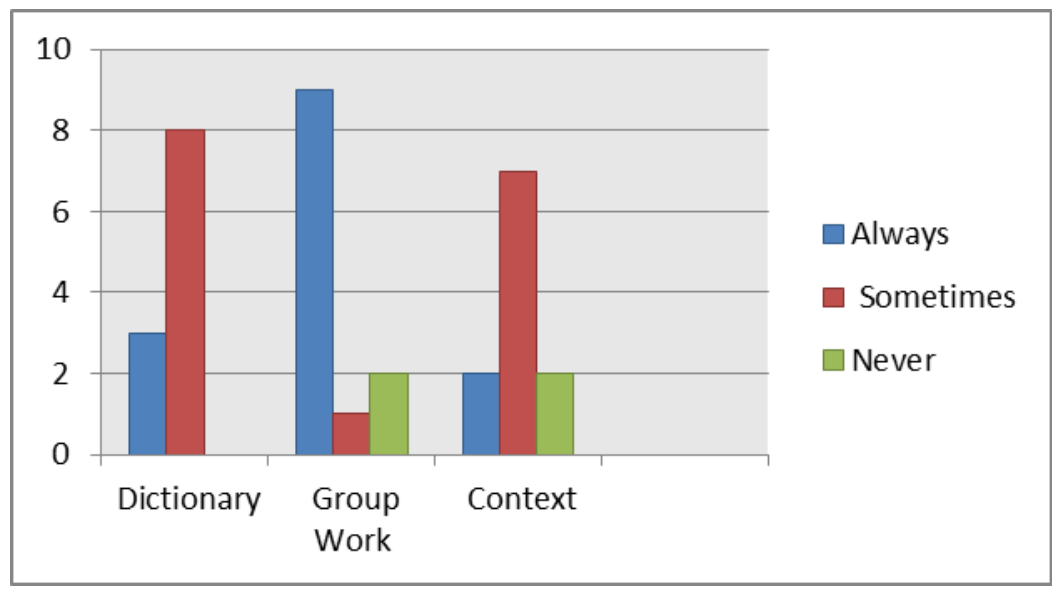

Figure 2. How students learn vocabulary

On the other hand, figure 2 . demonstrates the most effective vocabulary learning methods according to the questionnaire distributed among students. First, group work was the most favorable learning activity among the others. $90 \%$ of the students approved that they learn new words from working in groups to accomplish a given task. However, $10 \%$ of them said they hardly learn new vocabulary words from working in groups. Secondly, eight students said they sometimes refer to dictionaries to help them translate unknown vocabulary words to their first language. Further, three of them mentioned that they always refer to dictionaries to look for word meanings in their L1. Generally, this finding supports Xu's hypothesis, which explained that the use of dictionary has a positive impact on vocabulary learning and reading development, especially that none of the students mentioned that they never use dictionary. Finally, learning words from context was the least favorable method of vocabulary learning. $70 \%$ of the students stated that they sometimes put unknown words in sentences to understand and to remember the given words. On the other hand, $20 \%$ of the students reported that they never use words in context to learn new vocabulary.

\section{Discussion}

During the class observation, students were more engaged in group work activities than they did when they worked individually. They were very active in negotiations and finding the possible answers for the questions given in the class, which relatively challenges one of Newton's findings (2013) that claimed negotiation does not account for most vocabulary learning. In addition, students demonstrated a good knowledge of vocabulary, and this was obvious when they worked in pairs. Further, students enjoyed the picture activity and they were active in it, which indicate that imagery can definitely help students in acquiring new vocabulary and attract their attention (Cohen \& Johnson, 2011).

\section{Conclusion and Pedagogical Implications}

The purpose of this paper was to investigate the vocabulary learning behavior among ESL learners. The study conducted in this research clearly explained how advanced ESL students learn vocabulary and the methods that English language learners usually prefer in learning second language (L2) vocabulary. The results showed that students learn vocabulary mostly from Reading classes and through group work. Therefore, ESL teachers are strongly encouraged to investigate their students' favorite learning method to optimize the vocabulary learning experience. Teachers can create formative assessments (e.g. a questionnaire or one-on-one interviews) to inquire about the students' language learning behavior. Making use of the information provided in this study, teachers should be able to develop effective vocabulary classes. It also can be helpful for the teachers to plan the class activities accordingly.

As vocabulary learning is the foundation of acquiring any language, teachers can implement different activities inside the classroom to maximize the students' capacity in learning new words. It is always recommended to: (1) introduce new words with visual stimuli to better engage the learners. It is also important to (2) keep new words practical; as it will let students know how and when to use these new words exactly. In fact, building ESL vocabulary is essential to language growth. Lastly, (3) having students learn new vocabulary in groups can be highly informative, especially for lower level students. Mingling lower level students with higher level students can help boost the confidence of the weaker students as they learn from their advanced peers. Ultimately, knowing how students better learn vocabulary can definitely help achieving the ESL teaching and learning goals, 
and facilitate the learning experience.

\section{References}

Alsubaie, J., \& Ashuraidah, A. (2017). Exploring Writing Individually and Collaboratively Using Google Docs in EFL Contexts. English Language Teaching, 10(10), 10. https://doi.org/10.5539/elt.v10n10p10

Bennett, R. E. (2011). Formative assessment: A critical review. Assessment in Education: Principles, Policy \& Practice, 18(1), 5-25. https://doi.org/10.1080/0969594X.2010.513678

Cho, K.-S., \& Krashen, S. (1994). Acquisition of Vocabulary from the Sweet Valley Kids Series: Adult ESL Acquisition. Journal of Reading, 37, 662-667.

Cohen, M. T., \& Johnson, H. L. (2010). Improving the Acquisition of Novel Vocabulary Through the Use of Imagery Interventions. Early Childhood Education Journal, 38(5), 357-366. https://doi.org/10.1007/s10 643-010- 0408-y

Elley, W. B. (1991). Acquiring Literacy in a Second Language: The Effect of Book-Based Programs. Language Learning, 41(3), 375-411. https://doi.org/10.1111/j.1467-1770.1991.tb00611.x

Etikan, I., Musa, S. A., \& Alkassim, R. S. (2015b, December 22). Comparison of Convenience Sampling and Purposive Sampling. American Journal of Theoretical and Applied Statist. Retrieved November 29, 2018, from http://article.sciencepublishinggroup.com/pdf/10.11648.j.ajtas.20160501.11.pdf

He, H., \& Deng, Y. (2015). The Mental Lexicon and English Vocabulary Teaching. English Language Teaching, 8(7). https://doi.org/10.5539/elt.v8n7p40

Horst, M. (2005). Learning L2 Vocabulary through Extensive Reading: A Measurement Study. Canadian Modern Language Review, 61(3), 355-382. https://doi.org/10.3138/cmlr.61.3.355

Lightbown, P. M. (1992). Can they do it themselves? A comprehension-based ESL course for young children. Comprehension-based second language teaching: Current trends, 353-370.

Maftoon, P., Hamidi, H., \& Sarem, S. N. (2012). The effects of CALL on vocabulary learning: A case of Iranian intermediate EFL learners. Broad Research in Artificial Intelligence and Neuroscience, 3(4), 19-30.

McCrostie, J. (2007). Examining learner vocabulary notebooks. ELT Journal, 61(3), 246-255. https://doi.org/10. 1093/elt/ccm032

Newton, J. (2013). Incidental vocabulary learning in classroom communication tasks. Language Teaching Research, 17(2), 164-187. https://doi.org/10.1177/1362168812460814

Nordquist, R. (2018, April 11). English as a second language (ESL) definition. Retrieved from https://www.thoughtco.com/english-as-a-second-language-esl-1690599

Parry, K. (1991). Building a Vocabulary through Academic Reading. TESOL Quarterly, 25(4), 629. https://doi.org/10.2307/3587080

Stefansson, E. G. (2013). Second Language Acquisition: The Effect of Age and Motivation. Retrieved from http://skemman.is/en/stream/get/1946/15018/35741/1/BA_EinarG.pdf

Xu, X. (2010). Study on the Effect of Dictionary Use on Second Language Incidental Vocabulary AcquisitionAn Empirical Study of College English Vocabulary Learning Strategy. Journal of Language Teaching and Research, 1(4). https://doi.org/10.4304/jltr.1.4.519-523

APPENDIX: A questionnaire to Survey Students' experience with learning and acquiring vocabulary.

\section{A- Please choose the correct answers:}

(1) I learn vocabulary from ... (more than one answer is allowed)

- Reading classes.

- Writing classes.

- Listening \& speaking classes.

- Outside the classroom ( friends, books, movies, ...etc)

(2) I use dictionary to help me translate English words into my $1^{\text {st }}$ language.

- Always. 
- Sometimes.

- Never.

(3) I write new words in a sentence so I can remember it.

- Always.

- Sometimes.

- Never.

(4) I learn new words when working in groups.

- Yes.

- No.

- Sometimes.

\section{B- Please answer the following question:}

(1) What is your favorite way to learn vocabulary inside the classroom?

\section{Copyrights}

Copyright for this article is retained by the author(s), with first publication rights granted to the journal.

This is an open-access article distributed under the terms and conditions of the Creative Commons Attribution license (http://creativecommons.org/licenses/by/4.0/). 